\title{
Insulin resistance in the course of acne - literature review
}

\author{
Anna Sadowska-Przytocka ${ }^{1}$, Michalina Gruszczyńska², Anna Ostałowska², Patrycja Antosik², \\ Magdalena Czarnecka-Operacz ${ }^{1}$, Zygmunt Adamski ${ }^{1}$, Katarzyna Łącka ${ }^{3}$
}

\author{
'Department of Dermatology, Poznan University of Medical Sciences, Poznan, Poland \\ ${ }^{2}$ Student's Scientific Circle at the Department of Endocrinology, Metabolism and Internal Diseases, Poznan University of Medical \\ Sciences, Poznan, Poland \\ ${ }^{3}$ Department of Endocrinology, Metabolism and Internal Diseases, Poznan University of Medical Sciences, Poznan, Poland
}

Adv Dermatol Allergol 2022; XXXIX (2): 231-238

DOI: https://doi.org/10.5114/ada.2021.107101

\begin{abstract}
Acne vulgaris is a very common skin disease being diagnosed in Westernized populations, however, its multifactorial etiopathogenesis still remains unclear. Recent research has demonstrated a possible linkage between acne and insulin resistance (IR), which is the topic of our review. In addition to an inappropriate diet, excessive androgen production or obesity, it is the IR which might be responsible for lack of efficacy of classical treatment strategy in acne. Interestingly, in all such cases an increased activity of mammalian target of rapamycin kinase complex 1 (mTORC1) has been detected. This observation might be considered as the basis of the possible role of metformin as an adjunct therapeutic modality for patients suffering from acne. The aim of our review is to present the possible etiological correlation between acne and insulin resistance, as well as metformin therapy, which might be highly useful in the treatment to resistant forms of acne.
\end{abstract}

Key words: acne vulgaris, resistant acne, insulin resistance, metformin.

\section{Introduction}

Recently a growing interest concerning the possible relationship between acne and insulin resistance (IR) has been noticed. It seems that acne being a chronic inflammatory skin disease might be strongly associated with IR [1]. When diagnosing this disease as well as composing the treatment strategy, IR evaluation seems to be highly important. Both disorders share the same signal transduction pathways, i.e. mammalian target of rapamycin kinase 1 (mTORC1) and insulin-like growth factor-1 (IGF-1) [2]. Nevertheless, correlating acne with IR still remains a diagnostic challenge. Various methodologies for IR evaluation have been proposed, such as euglycemic metabolic clamp, Homeostasis Model Assessment (HOMAindex) and Quantitative Insulin Sensitivity Check Index (QUICKI) [3]. Clinical severity of acne may be evaluated with scoring systems such as GAGS (Global Acne Grading System) [4] or AFAST (Adult Female Acne Scoring Tool) [5]. Still, there is no method, which would provide a certain diagnosis of both coexisting IR and acne in a single test.

According to the updated literature, acne affects more than $85 \%$ of teenagers [2], and even highly sophisticated therapeutic modalities are sometimes not effective. In addition, lots of attention have been paid to various side-effects of the acne therapy and many research projects have been focused on the topic of reduction in adverse events, while new targeted acne treatment remained unsolved [6]. Due to certain pathogenetic similarities between acne and IR, proper treatment of IR might result in clinical improvement of acne.

The aim of our review was to evaluate a possible role of IR in the etiopathogenesis of acne as well as to analyse the efficacy of IR treatment being one of the therapeutic modalities within the treatment strategy of acne patients.

\section{Acne}

Acne is a relatively common chronic inflammatory skin disease involving folliculopilosebaceous unit. Women and adolescents constitute the majority of patients affected by acne [1]. Skin lesions such as comedones, papules, pustules or nodules are generally located within the skin of the face, shoulders, back and chest [1]. Widely-known acne is divided into three categories, related to the severity of the disease: mild, moderate and severe [4].

Address for correspondence: Anna Sadowska-Przytocka PhD, Department of Dermatology, Poznan University of Medical Sciences, Poznan, Poland, phone: +48 661-964-960, e-mail: a.sadowska80@gmail.com Received: 7.09.2020, accepted: 30.11.2020. 
Acne is a very heterogeneous disorder associated with highly complex etiopathology. It includes excess production of sebum (hyperseborrhea), hyperkeratosis and inflammation [7]. Many transcription factors such as forkhead box protein 01 (FoxO1), 1,25-dihydroxyvitamin $\mathrm{D}$ and calcium are connected with sebum production [8].

Abnormal hormones function - hyperandrogenemia, hyperinsulinemia and an elevated level of insulin growth factor-1 (IGF-1) have the crucial role in the acne development as well. Hyperinsulinemia is responsible for increased proliferation and dysfunction of keratinocytes by stimulation of IGF-1 receptors. Hypersecretion of IGF-1 leads to abnormal sebum production, hyperproliferation of sebocytes and lipogenesis [1]. The synthesis of androgens is promoted by insulin and IGF-1. Moreover, IGF-1 enhances androgen receptor signal transduction. As a consequence, the elevated androgen level encourages hyperseborrhea [1].

Acne vulgaris tends to be regarded as a disease of Western civilization due to the fact that the increased serum level of insulin/IGF-1 is in addition significantly correlated with a high intake of carbohydrates, insulinotropic milk and dairy products [2]. In the study published by Cerman et al., higher dietary glycaemic load and milk consumption in acne patients in comparison to the control group have been proven [9], whereas acne has not been observed in populations with a Palaeolithic type of eating habits [2]. The hyperglycaemic diet activates mTORC1 leading to both dysfunction of the sebaceous gland and development of IR via ribosomal protein S6 kinase $\beta 1$ (S6K1) [1] and supresses FoxO1, which is responsible for repressing the androgen receptor, androgen signalling, synthesis of hepatic IGF-1 and regulating lipogenesis. Inactivated, does not influence on mTORC1 [1]. Consumption of a lower amount of products mentioned above decreases severity of inflammation, lowers production of proinflammatory chemokines and reduces the size of sebaceous glands [1]. The relationship between acne and lifestyle habits has been further investigated by many researchers. Stewart et al. have recorded statistically significant concomitance of vitamin D deficit and a positive tissue transglutaminase antibody serum level whereas no correlation of the vegan diet or increased body mass index (BMI) with acne development has been proven [10]. Snast et al. confirmed that overweight and obesity are inversely associated with acne [11]. Moreover, a positive correlation between the higher BMI and severity of acne has been recorded [12].

The role of Cutibacterium acnes in the pathogenesis of acne still remains unclear. There is no significant difference in terms of skin colonization with $C$. acnes between acne patients and patients without signs and symptoms of the disease. Therefore, it has been absolutely clear already for a long time that $C$. acnes and proliferation of this microbe within the skin of patients are not the basic causative factors in acne $[8,13]$. Nevertheless, abnormal load of C. acnes is linked to sebaceous follicles due to a high concentration of lipids in this area [1]. S. epidermidis inhibits proliferation of $C$. acnes therefore modification of skin microbiota is considered to be a logical treatment modality in acne [13].

Acne may also occur in the course of many endocrinological disorders. An intensified sebum excretion rate in patients with acromegaly was observed by Burton et al. in 1972 [14]. Growth hormone (GH) induces production of IGF-1 stimulating lipogenesis and $5 \alpha$-reductase. Testosterone and DHT formed in excess lead to enlargement of the sebaceous gland, excessive sebum secretion and therefore provoking acne skin lesions [15]. The reverse situation is presented by patients suffering from Laron syndrome characterized by IGF-deficiency. It has been observed that a significant lack of IGF prevented development of acne [16].

It has been recorded that structural similarity between GH and prolactin may cause IR in the course of hyperprolactinemia [17]. Langan et al. have indicated that prolactin itself may stimulate sebocytes proliferation [18].

Most of the patients with congenital adrenal dysplasia (CAH) present a specific defect of 21-hydroxylase which prompts the deficit of cortisol and aldosterone [19]. It leads to ACTH production increase and stimulation of excessive adrenal androgens production. Treatment of $\mathrm{CAH}$ is based on supplementation of glucocorticoids which can stimulate expression of Toll-like receptors, which bind the peptidoglycan structure of the $C$. acnes cell wall, and finally triggering the immune response [15].

The most common disorders associated with polycystic ovary syndrome (PCOS) are hyperandrogenism, dysfunction of the menstrual cycle and polycystic ovarian morphology [20].

However, acne in PCOS patients may be triggered not only by excessive androgen production, but also by presence of IR which often coexists with PCOS [20].

\section{Insulin resistance}

IR is defined as an inability of insulin to provide appropriate glucose transport into metabolic tissues such as the skeletal muscle, adipose tissue, and liver, despite its normal or elevated secretion. As a consequence, IR is responsible for development of hyperglycaemia and hyperinsulinemia [17]. IR may be caused both by genetic and environmental factors [21]. Up till now various genetic loci related to the increased risk of IR have been identified. So have been those associated with glucose metabolism, insulin activities, signalling in insulin-dependent tissues or insulin and IGF receptors activation [22].

A wide spectrum of various etiopathological factors in the development of IR have been reported. Obesity seems to be one of the most common $[23,24]$. In addition, chronic inflammation $[25,26]$, hypertriglyceridemia, low HDL serum concentration [27], mitochondrial 
dysfunction [28], gut microbiota [29], the excess activity of antagonistic hormones such as cortisol, glucagon, thyroid hormones seems to play a significant role [17]. The high risk of developing IR and hyperinsulinemia is associated with certain living habits such as smoking [30], and a high intake of milk and carbohydrates [2].

$\mathrm{IR}$ is included as a component of the metabolic syndrome [31] and it is an independent risk factor for cardiovascular diseases [28, 32], type 2 diabetes [26, 32] and non-alcoholic fatty liver disease [33]. It may coexist also with impaired glucose tolerance or hypertension [17]. IR is also associated with the whole variety of endocrine disorders such as acromegaly, hyperprolactinemia, hypercortisolism, hypopituitarism, hyper- and hypothyroidism, primary hyperparathyroidism, pheochromocytoma, primary aldosteronism, congenital adrenal hyperplasia (CAH), PCOS and hypogonadism [17].

Diagnostics of IR is rather complicated. Euglycemic metabolic clamp described by R. A. DeFronzo, J. D. Tobin and R. Andres in 1979 is regarded to be the golden standard. It requires constant intravenous infusions of insulin to suppress the function of B-cells, in parallel to intravenous glucose infusion administered to achieve the status of euglycaemia. The amount of infusions corresponds with glucose uptake by peripheral tissues. Insulin resistance is calculated based on the number of glucose infusates provided and body weight. Euglycemic metabolic clamp enables assessment of peripheral tissue as well as B-cell sensitivity to insulin [34, 35]. Unfortunately the clinical value of this methodology is limited due to its complexity.

Homeostasis Model Assessment (HOMA) is generally one of the basic and frequently used methods in terms of IR diagnostics. This method is based on evaluation of serum levels of both fasting glucose and insulin. D. R. Matthews et al. have proposed to collect three blood samples in 5 min' intervals in order to improve the quality of results obtained [34, 35]. Further an "insulin $\times$ glucose/22.5" formula of calculation is recommended. Unfortunately a standardised cut-off value is still not established and therefore we are facing significant difficulties using HOMA methodology in our clinical practice. Geloneze et al. have identified the cut-off values above 2.7 HOMA1-IR and above 1.8 HOMA2-IR [36]. For the study on the Polish population, Szurkowska et al. have considered IR cut-off values as above 2.1 HOMA-IR [37]. GayosoDiz et al. in their study have suggested that the cut-off value should be established in relation to the age and gender of investigated patients [38].

Another widely-used method is the Quantitative Insulin Sensitivity Check Index (QUICKI). It considers fasting insulin and glucose serum level measurements as well and a significant correlation with glucose clamp has been proven [3]. Unfortunately different cut-off values are being set by different laboratories due to various methodology applied for insulin serum level measure- ments [39]. Matsuda index considers not only fasting glucose and insulin serum level measurements, but also their mean concentrations during the oral glucose tolerance test (OGTT) measured $120 \mathrm{~min}$ and $180 \mathrm{~min}$ from the $75 \mathrm{~g}$ glucose consumption. In this case both hepatic and peripheral tissues' sensitivity to insulin is being evaluated [39].

McAuley et al. have proposed a different type of measurements to diagnose IR in the general population. According to the authors, serum levels of fasting insulin and triglycerides provide the best predictive value [40].

A wide range of methods available to select from may also be responsible for certain difficulties in the process of IR diagnostics. HOMA-IR, despite its wide application in scientific research and significant correlation with the glucose clamp, presents a relatively limited importance in the clinical practice due to unclear standardized cut-off values. There are no typical clinical symptoms of IR. Regardless of a strong correlation between metabolic syndrome and IR, patients with normal BMI may also suffer from IR [41].

\section{Relationship between acne and insulin resistance}

As mentioned above, acne seems to be strongly associated with IR [1] but the role of IR in the pathogenesis of acne is still not clearly understood. High glycaemia induces both synthesis and secretion of insulin, which encourages ovaries and adrenal glands to produce androgens. It can also lower the serum level of sex hormonebinding globulin (SHBG) and therefore strongly intensify androgen activity and facilitate development of acne [42]. Insulin also decreases IGF-1 binding protein, which causes a significant rise of the free IGF-1 serum level [15]. Smith et al. have demonstrated that IGF-1 stimulates lipogenesis in SEB-1 sebocytes through activation of the Phosphoinositide 3-kinase (PI3-K)/Akt pathway, which leads to the enhanced expression of sterol regulatory element-binding protein-1 (SREBP-1) [43].

In patients with acne, an increased MTORC1 activity has been detected, which is strongly associated with IR, obesity, type 2 diabetes and cancers such as melanoma and prostate cancer [2]. IR seems to be induced via insulin receptor substrate-1 phosphorylation due to the activation of S6K1 kinase related to an increased activity of mTORC1. Also, a significant correlation between a decreased expression of insulin, IGF-1 and MTORC1 and a reduced prevalence rate of acne has been observed [2].

In case of young males, IR in the course of acne has been reported in the literature. Nagpal et al. have noticed a significant correlation between HOMA-IR value and acne development. However, no statistically significant difference between HOMA-IR value, metabolic syndrome and acne severity has been observed [44]. 
In the study of Del Prete et al. performed in the male population of acne patients, a significant correlation between the acne score and HOMA-IR has been noticed, with exclusion of any possible impact of the abnormal androgenic profile, evaluated based on measurements of serum levels of free testosterone, total testosterone, dehydroepiandrosterone sulfate (DHEAS) and SHBG. Therefore, it has been concluded that acne might have been caused only by hyperinsulinemia, and not by intensified androgen activity [45]. Kartal et al. have reported that IR is a risk factor for acne which is independent of hyperandrogenemia as well [46]. Likewise Emiroglu et al. have received the results of a significantly higher HOMA value in male and female acne patients $(\mathrm{HOMA}=2.87)$, and the value suggested that the IR had already developed [16] Whereas Cerman et al. have found lower adiponectin levels in acne patients [9]. Adiponectin increases insulin sensitivity, and so its deficit is a risk factor for IR development (Table 1).

A significant correlation between HOMA values and the incidence of acne has been reported by Emiroglu et al., Nagpal et al. and Del Prete et al.

However, some studies have reported no correlation between IR and acne development. Balta et al. have found no significant differences in the serum concentrations of fasting blood glucose, fasting insulin and HOMA$\mathrm{IR}$ value between patients suffering from post-adolescent acne and the control group [47]. Cetinözman et al. have not concluded any association between severe acne and hyperandrogenemia or insulin resistance as well [48] (Figure 1).

\section{Treatment of acne}

Treatment methods depend on the clinical features and variants of acne [49]. Severity of acne and previous treatment have an influence on modality of the therapy as well. Some patients may be satisfied with topical treatment only, however, systemic treatment or both methods combined usually bring more satisfactory effects.

In the treatment of comedonal acne, topical retinoid is recommended. Adapalene is preferred over tretinoin or isotretinoin [49]. Azelaic acid (AA) and benzoyl peroxide (BPO) can be considered as well [49] due to their comedolytic and antibacterial properties [50-52]. Moreover, AA can be used during pregnancy and breastfeeding [53], whereas adapalene and BPO may prompt photosensitivity and skin irritations, therefore should be used with caution [54].

Mild to moderate papulopustular acne can also be treated with topical medications. The combinations of adapalene + BPO or BPO + clindamycin are strongly recommended. The monotherapy of AA, BPO or topical retinoid may be prescribed as well. Topical antibiotic + tretinoin or systemic antibiotic + adapalene therapies can be induced, however, each antibiotic prescription should be well considered due to the potential risk of antibiotic resistance development in local $C$. acnes and other cutaneous bacteria including staphylococci [49]. Resistance to clindamycin and erythromycin is more common than resistance to tetracyclines [49]. Despite the side effect of photosensitivity, doxycycline and lymecycline are recommended, however their use is limited to the period of 3 months [49].

Severe papulopustular, nodular and conglobate acne requires oral isotretinoin as the first-choice treatment [49]. Retinoids lower sebum production by affecting retinoids acid receptors (RARs) [55]. They also have comedolytic properties and suppress formation of new lesions [51]. By stimulating the expression of p53, retinoids lead to an increased serum level of IGF binding protein 3 and reduced androgen and IGF-1 receptors formation [56]. Retinoids display anti-inflammatory activity by inhibiting

Table 1. HOMA values in acne patients and controls $[9,16,44,45]$

\begin{tabular}{|c|c|c|c|c|c|c|c|c|c|c|c|c|}
\hline \multirow{3}{*}{$\begin{array}{l}\text { Para- } \\
\text { meter } \\
\text { Author } \\
\text { Group }\end{array}$} & \multicolumn{3}{|c|}{$\begin{array}{l}\text { Insulin resistance in severe } \\
\text { acne vulgaris }\end{array}$} & \multicolumn{3}{|c|}{$\begin{array}{c}\text { Dietary glycemic factors, } \\
\text { insulin resistance and } \\
\text { adiponectin levels in acne } \\
\text { vulgaris }\end{array}$} & \multicolumn{3}{|c|}{$\begin{array}{l}\text { Insulin resistance and } \\
\text { metabolic syndrome in } \\
\text { young men with acne }\end{array}$} & \multicolumn{3}{|c|}{$\begin{array}{l}\text { Insulin resistance in acne: } \\
\text { a new risk factor for men? }\end{array}$} \\
\hline & \multicolumn{3}{|c|}{ Nazan Emiroglu et al., 2014} & \multicolumn{3}{|c|}{ Cerman et al., 2016} & \multicolumn{3}{|c|}{ Nagpal et al., 2018} & \multicolumn{3}{|c|}{ del Prete et al., 2012} \\
\hline & Patients & Controls & $P$-value & Patients & Controls & $P$-value & Patients & Controls & $P$-value & Patients & Controls & $P$-value \\
\hline Number & 243 & 156 & & 50 & 36 & & 100 & 100 & & 22 & 22 & \\
\hline Gender & $\begin{array}{l}40.7 \% \\
\text { males }\end{array}$ & $\begin{array}{l}28.8 \% \\
\text { males }\end{array}$ & & $\begin{array}{l}44 \% \\
\text { males }\end{array}$ & $\begin{array}{l}38.9 \% \\
\text { males }\end{array}$ & & $\begin{array}{l}100 \% \\
\text { males }\end{array}$ & $\begin{array}{l}100 \% \\
\text { males }\end{array}$ & & $\begin{array}{l}100 \% \\
\text { males }\end{array}$ & $\begin{array}{l}100 \% \\
\text { males }\end{array}$ & \\
\hline Age & $19.94 \pm 4.77$ & $19.22 \pm 0.69$ & 0.05 & $18.8 \pm 3.2$ & $19.06 \pm 3.49$ & 0.747 & $22.7 \pm 3.0$ & $23.7 \pm 3.0$ & 0.06 & $18.6 \pm 2.5$ & $20.2 \pm 3$ & 0.06 \\
\hline BMI & $22.6 \pm 2.95$ & $22.3 \pm 3.52$ & 0.05 & $21.16 \pm 1.86$ & $21.69 \pm 1.58$ & 0.07 & $22.9 \pm 4.0$ & $23.4 \pm 3.2$ & 0.37 & $24 \pm 2.8$ & $20.1 \pm 1.5$ & 0.003 \\
\hline Glucose & $82.91 \pm 9.8$ & $80.26 \pm 8.4$ & 0.111 & $84 \pm 7.72$ & $83.67 \pm 8.33$ & 0.849 & $88.2 \pm 8.3$ & $84.5 \pm 11.2$ & 0.008 & $88.9 \pm 7.8$ & $84.3 \pm 5.9$ & 0.03 \\
\hline Insulin & $14.01 \pm 11.99$ & $9.12 \pm 3.55$ & 0.001 & $9.72 \pm 6.26$ & $9.88 \pm 4.3$ & 0.384 & $9.2 \pm 8.5$ & $7.8 \pm 6.8$ & 0.22 & $10.6 \pm 8.4$ & $5.5 \pm 1.4$ & 0.01 \\
\hline HOMA & $2.87 \pm 2.572$ & $1.63 \pm 0.663$ & 0.001 & $2.03 \pm 1.49$ & $2.05 \pm 0.93$ & 0.37 & $2.0 \pm 1.8$ & $1.7 \pm 2.3$ & 0.04 & $1.7 \pm 0.8$ & $1.1 \pm 0.3$ & 0.016 \\
\hline
\end{tabular}


secretion of cytokines such as IL-6, IL-12, TNF- $\alpha$, IFN- $\gamma$ and TLR-2 production in monocytes [57]. Furthermore they suppress the expression of transcription factor activator protein (AP-1) and vascular cell adhesion molecule-1 gene [57]. Incontrovertible disadvantages of retinoids are side effects. Oral isotretinoin treatment requires periodic assessment of the liver function (liver enzymes, lipidogram) and birth control due to teratogenicity. A study performed by Dikicier has shown that most of the patients give up retinoid treatment due to its side effects [58]. Some researchers have pointed that a small dose of retinoids may boost sebocytes [55]. Soyuduru et al. have suggested that 5 months' isotretinoin therapy leads to insulin resistance, and it is not related with age, BMI or lipid levels [59].

Systemic antibiotics with BPO, AA or adapalene are also recommended in the severe acne treatment. Hormonal antiandrogens combined with systemic antibiotics and topical preparations constitute an alternative for women. Oral contraceptive pills (OCPs) increase the level of SHBG which connects with testosterone leading to its inactivation [51]. We cannot unanimously state which progestin type involving chlormadinone acetate, cyproterone acetate, levonorgestrel or desogestrel brings the most satisfactory acne improvement [49].

AA, topical retinoid, adapalene + BPO, low-dose systemic isotretinoin or hormonal treatment may be considered as the maintenance therapy as well [49] (Figure 2).

\section{Metformin}

Metformin has a positive impact on glucose transporter type 4 (GLUT4) by increasing the expression of GLUT4 mRNA [60] and suppressing endocytosis of GLUT4 via AMP-activated protein kinase (AMPK) pathway [61]. Both mechanisms lead to a rise in GLUT4 and therefore insulin sensitivity enhancement, reducing the serum insulin level and its effects. Activation of AMPK inhibits mTORC1 which is upregulated in acneic skin and due to that suppresses sebum overproduction, which is beneficial to acne treatment [57]. Metformin regulates glycaemia not only by affecting liver metabolism, but also by increasing glucose utilization in muscles and adipocytes when elevating the level of glucagon-like peptide-1 (GLP-1) [62]. It can also suppress proinflammatory cytokine secretion and inhibit differentiation of monocytes, which lead to limitation of the inflammation [62]. Metformin reduces high serum levels of IGF-1 and androgen in women with PCOS [63]. As we have mentioned before, IGF-1 stimulates hypersecretion of sebum and therefore promotes development of acne. The obvious contribution of high-glycaemic load diet, milk consumption and lack of physical activity to the development of IR must be considered in the treatment strategy. Modification of lifestyle factors is a significant component of the IR therapy $[2,17,21]$.

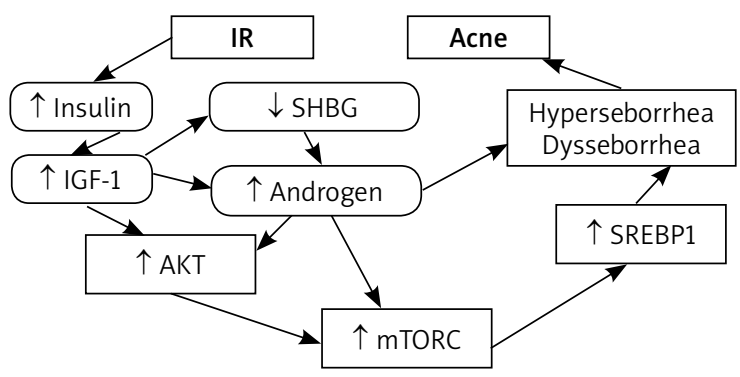

$S H B G$ - sex hormone binding globulin, $A K T$ - protein kinase $B, m T O R C 1$ - mammalian target of rapamycin kinase 1, SREBP-1 - sterol regulatory element-binding protein 1.

Figure 1. Correlation between IR and acne

Table 2 presents data regarding to the effectiveness of metformin treatment modality to the patients suffering from acne vulgaris [64-67].

All the data presented have demonstrated the effectiveness of metformin as an adjuvant therapy of acne. Only slight gastrointestinal side effects of this type of therapy have been observed.

It seems that only oral treatment with isotretinoin might cause a more significant reduction in GAGS value, however this phenomenon does not apply to PCOS patients. Moreover, metformin, contrary to oral isotretinoin, presents a positive metabolic characteristics.

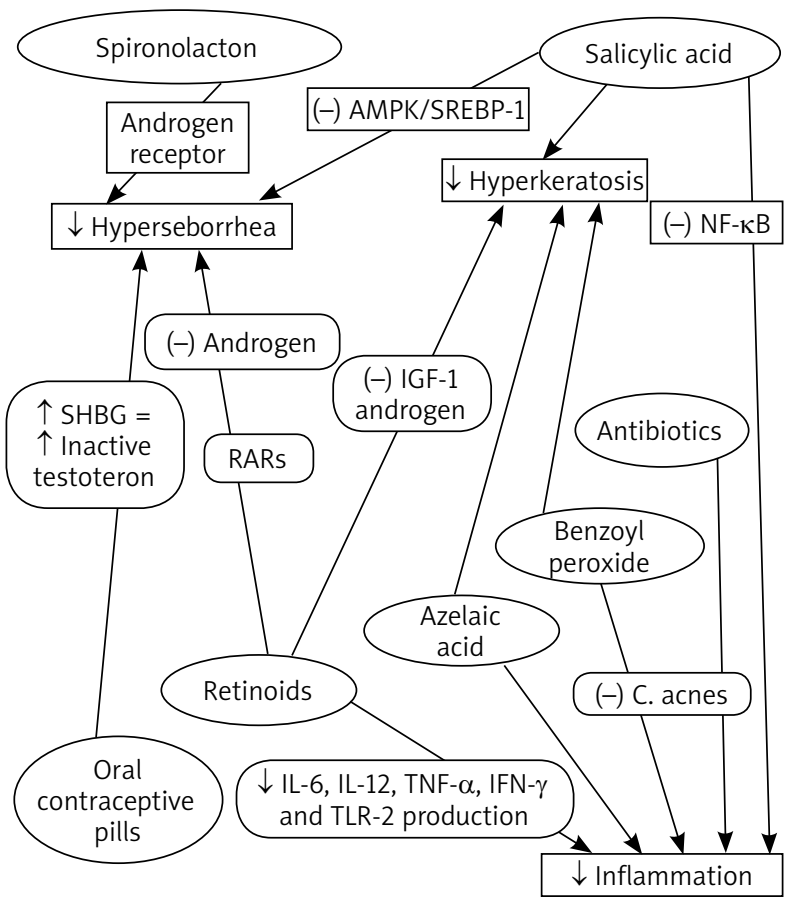

RARS - retinoic acid receptors, AMPK - AMP-activated protein kinase, SREBP-1 - sterol regulatory element-binding protein $1, N F-\kappa B-$ nuclear factor $\kappa$-light-chain-enhancer of activ ated B cells, SHBG - sex hormone binding globulin.

Figure 2. Classical methods for treatment of acne 
Anna Sadowska-Przytocka, Michalina Gruszczyńska, Anna Ostałowska, Patrycja Antosik, Magdalena Czarnecka-Operacz, Zygmunt Adamski, Katarzyna Łącka

Table 2. Review of the effectiveness of metformin treatment in acne vulgaris patients [64-67]

\begin{tabular}{|c|c|c|c|c|c|c|c|c|}
\hline Parameter & \multicolumn{2}{|c|}{$\begin{array}{l}\text { The effect of metformin } \\
\text { in the treatment } \\
\text { of intractable and } \\
\text { late onset acne: } \\
\text { a comparison with oral } \\
\text { isotretinoin }\end{array}$} & \multicolumn{2}{|c|}{$\begin{array}{l}\text { Low glycamic diet and } \\
\text { metformin therapy: a new } \\
\text { approach in male subjects } \\
\text { with acne resistant to common } \\
\text { treatments }\end{array}$} & \multicolumn{2}{|c|}{$\begin{array}{c}\text { DB-RCT on the efficacy } \\
\text { and safety of metformin } \\
\text { adjunct to lymecyclie and } \\
\text { topical adapalen/BPGel in } \\
\text { mod-severe acne }\end{array}$} & \multicolumn{2}{|c|}{$\begin{array}{l}\text { Metformin as an adjunct } \\
\text { therapy for the treatment } \\
\text { of moderate to severe acne } \\
\text { vulgaris a randomized } \\
\text { open-labeled study }\end{array}$} \\
\hline Author, date & \multicolumn{2}{|c|}{ Behrangi et al., 2019} & \multicolumn{2}{|c|}{ G. Fabbrocini et al., 2016} & \multicolumn{2}{|c|}{ Nina Gabaton, 2016} & \multicolumn{2}{|c|}{ Robinson et al., 2019} \\
\hline Group & Metformin & Isotretinoin & Metformin & Controls & Metformin & Controls & Metformin & Controls \\
\hline $\begin{array}{l}\text { Number, } \\
\text { gender }\end{array}$ & $\begin{array}{c}35 \\
\text { females }\end{array}$ & 35 females & 10 males & 10 males & $20 \mathrm{M} / \mathrm{F}$ & $20 \mathrm{M} / \mathrm{F}$ & 42 & 42 \\
\hline Age & \multicolumn{2}{|c|}{$32.2 \pm 4.3$} & \multicolumn{2}{|c|}{$17-24(19.5)$} & \multicolumn{2}{|c|}{$16-45$} & & \\
\hline $\begin{array}{l}\text { Medications } \\
\text { provided }\end{array}$ & $\begin{array}{c}\text { Metformin } \\
2 \times 500 \\
\mathrm{mg}\end{array}$ & $\begin{array}{l}\text { Isotretinoin } \\
1 \times 20 \mathrm{mg}\end{array}$ & $\begin{array}{l}\text { Metformin } \\
2 \times 500 \mathrm{mg} \\
\text { Hypocaloric diet } \\
\text { Azelaic acid, } \\
\text { nicotinamid }\end{array}$ & $\begin{array}{l}\text { Azelaic acid, } \\
\text { nicotinamid }\end{array}$ & $\begin{array}{l}\text { Metformin } \\
\text { Adapalen/ } \\
\text { BPGel } \\
\text { Lymecycline } \\
6 \text { weeks }\end{array}$ & $\begin{array}{l}\text { Placebo } \\
\text { Adapalen/ } \\
\text { BPGel } \\
\text { Lymecycline } \\
6 \text { weeks }\end{array}$ & $\begin{array}{l}\text { Metformin } \\
1 \times 850 \mathrm{mg} \\
\text { Tetracycline } \\
250 \mathrm{mg} \\
\text { BPGel } 2.5 \%\end{array}$ & $\begin{array}{c}\text { Tetracycline } \\
250 \mathrm{mg} \\
\text { BPGel } 2.5 \%\end{array}$ \\
\hline Time & \multicolumn{2}{|c|}{6 months } & \multicolumn{2}{|c|}{6 months } & \multicolumn{2}{|c|}{18 weeks } & \multicolumn{2}{|c|}{12 weeks } \\
\hline Acne $\mathrm{T}^{\circ}$ & $\begin{array}{c}\text { GAGS }= \\
31.9\end{array}$ & GAGS = 34.1 & GAGS $=25.1 \pm 8.9$ & $\mathrm{GAGS}=24.9 \pm 7.6$ & & & & \\
\hline $\begin{array}{l}\text { Acne } \\
\text { improval }\end{array}$ & $\begin{array}{c}\text { GAGS } \\
=24.6 \\
\text { PCOS- } \\
\text { GAGS = } \\
13.5\end{array}$ & $\begin{array}{l}\text { GAGS = 13.3 } \\
\text { PCOS-GAGS } \\
=24.2\end{array}$ & $\begin{array}{c}\text { GAGS }=14.1 \\
\pm 10.4\end{array}$ & $\begin{array}{c}\text { GAGS }=19.4 \\
\pm 7.4\end{array}$ & $\begin{array}{c}\text { Higher } \\
\text { reduction of the } \\
\text { inflammatory } \\
\text { and total lesion } \\
\text { count } \\
\text { Lower global } \\
\text { severity score }\end{array}$ & & $\begin{array}{l}\text { CADI index } \\
\text { reduce of } 4.82 \\
\text { Total lesions } \\
\text { counts } \\
\text { reduction of } \\
71.4 \%\end{array}$ & $\begin{array}{l}\text { CADI index } \\
\text { reduce of } \\
4.22 \\
\text { Total lesion } \\
\text { counts } \\
\text { reduction } \\
\text { of } 65.3 \%\end{array}$ \\
\hline Extra effects & $\begin{array}{l}\text { Increased } \\
\text { HDL, } \\
\text { decreased } \\
\text { LDL, FBS }\end{array}$ & $\begin{array}{l}\text { Increased } \\
\text { AST, ALT, } \\
\text { bilirubin }\end{array}$ & $\begin{array}{l}\text { Increased HDL } \\
\text { Decreased } \\
\text { HOMA-IR }\end{array}$ & & $\begin{array}{l}\text { Self-limited } \\
\text { systemic } \\
\text { adverse events } \\
\text { (diarrhea, } \\
\text { flatulence, } \\
\text { headache, } \\
\text { epigastric pain) }\end{array}$ & & $\begin{array}{l}\text { Gastrointestinal } \\
\text { symptoms in } \\
31.7 \%\end{array}$ & \\
\hline
\end{tabular}

Metformin does play a role not only in cutaneous disorders linked with hyperinsulinemia and hyperandrogenism such as acne or hirsutism, but also the treatment of acanthosis nigricans, eruptive xanthomas, hidradenitis suppurativa, psoriasis or skin cancers is proposed [68]. For hyperpigmentary lesions topical preparations of metformin could be applied [68]. Topical formulation throughout local suppression of the mTORC1 overexpression seems to be effective in the treatment of acne lesions in the future as well [69].

\section{Conclusions}

In our review paper a specific and possible relationship between acne development and IR has been presented on the basis of updated literature data. Increased mTORC1 signalling observed in both conditions mentioned above, seems to be an important factor and perhaps should be considered in the complex structure of treatment strategy in patients suffering from acne.
Also, IR might be a possible causative factor of resistance to a standard acne therapy in our clinical practice. Moreover, oral treatment with isotretinoin may induce $I R$, which might be responsible for relapses of acne after discontinuation of systemic isotretinoin therapy. Acne should be obviously considered to be a systemic disease, which requires a complex and personalised therapy. Metformin seems to be an effective and interesting therapeutic modality for patients with acne. Treatment with metformin not only reduces GAGS value, stabilisation of the lipid profile, as well as serum glucose and insulin levels have also been recorded. Therefore it seems to be important to consider metformin to be not only an adjuvant medication in the treatment of acne, but also an element of the preventive approach in terms of relapses of the disease. Obviously further studies including a bigger population of patients are required in order to prove this therapeutic modality to be an effective and safe element or alternative therapy in the daily, dermatological, clinical practice. 


\section{Conflict of interest}

The authors declare no conflict of interest.

\section{References}

1. Napolitano M, Megna M, Monfrecola G. Insulin resistance and skin diseases. Sci World J 2015; 2015: 479354.

2. Melnik BC. Acne vulgaris: the metabolic syndrome of the pilosebaceous follicle. Clin Dermatol 2018; 36: 29-40.

3. Katz A, Nambi SS, Mather K, et al. Quantitative insulin sensitivity check index: a simple, accurate method for assessing insulin sensitivity in humans. J Clin Endocrinol Metabol 2000; 85: 2402-10.

4. Gupta A, Sharma YK, Dash KN, et al. Quality of life in acne vulgaris: relationship to clinical severity and demographic data. Indian J Dermatol Venereol Leprol 2016; 82: 292-7.

5. Auffret N, Claudel JP, Leccia MT, et al. AFAST - Adult Female Acne Scoring Tool: an easy-to-use tool for scoring acne in adult females. J Eur Acad Dermatol Venereol 2016; 30: 824-8.

6. De Sousa VD. New and emerging drugs for the treatment of acne vulgaris in adolescents. Expert Opin Pharmacother 2019; 20: 1009-24.

7. Tan JKL, Stein Gold LF, Alexis AF, et al. Current concepts in acne pathogenesis: pathways to inflammation: insulin resistance and skin diseases. Semin Cutan Med Surg 2018; 37: 60-2.

8. Mwanthi M, Zaenglein AL. Update in the management of acne in adolescence. Curr Opin Pediatr 2018; 30: 492-8.

9. Çerman AA, Aktaş E, Altunay ik, et al. Dietary glycemic factors, insulin resistance, and adiponectin levels in acne vulgaris. J Am Acad Dermatol 2016; 75: 155-62.

10. Stewart TJ, Bazergy C. Hormonal and dietary factors in acne vulgaris versus controls. Dermatoendocrinology 2018; 10 : e1442160.

11. Snast I, Dalal A, Twig G, et al. Acne and obesity: a nationwide study of 600,404 adolescents. J Am Acad Dermatol 2019; 81: 723-9.

12. Seleit I, Bakry OA, Abdou AG, et al. Body mass index, selected dietary factors, and acne severity: are they related to in situ expression of insulin-like growth factor-1? Anal Quantitative Cytopathol Histopathol 2014; 36: 267-78.

13. Dréno B, Pécastaings $S$, Corvec $S$, et al. Cutibacterium acnes (Propionibacterium acnes) and acne vulgaris: a brief look at the latest updates. J Eur Acad Dermatol Venereol 2018; 32: 5-14.

14. Burton JL, Libman LJ, Cunliffe WJ, et al. Sebum excretion in acromegaly. Br Med J 1972; 12: 406-8.

15. Arora MK, Yadav A, Saini V. Role of hormones in acne vulgaris. Clin Biochem 2011; 44: 1035-40.

16. Emiroğlu N, Cengiz FP, Kemeriz F. Insulin resistance in severe acne vulgaris. Adv Dermatol Allergol 2015; 32: 281-5.

17. Rogowicz-Frontczak A, Majchrzak A, Zozulińska-Ziółkiewicz D. Insulin resistance in endocrine disorders - treatment options. Endokrynol Pol 2017; 68: 334-51.

18. Langan EA, Hinde E, Paus R. Prolactin as a candidate sebotrop(h)ic hormone? Exp Dermatol 2018; 27: 729-36.

19. Nermoen I, Husebye ES, Myhre AG, et al. Classic congenital adrenal hyperplasia. Tidsskr Nor Laegeforen 2017; 137: 540-3.

20. Mohammad MB, Seghinsara AM. Polycystic ovary syndrome (PCOS), diagnostic criteria, and AMH. Asian Pacific J Cancer Prev 2017; 18: 17-21.

21. Archer AE, Von Schulze AT, Geiger PC. Exercise, heat shock proteins and insulin resistance. Philosophical Transactions of the Royal Society of London. Series B: Biological Sciences 2018; 373.

22. Kalupahana NS, Moustaid-Moussa N, Claycombe KJ. Immunity as a link between obesity and insulin resistance. Mol Aspects Med 2012; 33: 26-34.

23. Brown AE, Walker M. Genetics of insulin resistance and the metabolic syndrome. Curr Cardiol Rep 2016; 18: 75.

24. Barazzoni R, Gortan Cappellari G, Ragni M, et al. Insulin resistance in obesity: an overview of fundamental alterations. Eat Weight Disord 2018; 23: 149-57.

25. Matulewicz N, Karczewska-Kupczewska M. Insulin resistance and chronic inflammation. Postepy Hig Med Dosw 2016; 70: 1245-58.

26. Glass CK, Olefsky JM. Inflammation and lipid signalling in the etiology of insulin resistance. Cell Metabolism 2012; 15: 635-45.

27. Li N, Fu J, Koonen DP, et al. Are hypertriglyceridemia and low $\mathrm{HDL}$ causal factors in the development of insulin resistance? Atherosclerosis 2014; 233: 130-8.

28. Kim J, Wei Y, Sowers JR. Role of mitochondrial dysfunction in insulin resistance. Circ Res 2008; 102: 401-14.

29. Caricilli AM, Saad MJA. The role of gut microbiota on insulin resistance. Nutrients 2013; 5: 829-51.

30. Haj Mouhamed D, Ezzaher A, Neffati F, et al. Effect of cigarette smoking on insulin resistance risk. Ann Cardiol Angéiol 2016; 65: 21-5.

31. Grundy SM, Brewer Jr HB, Cleeman JI, et al. Definition of metabolic syndrome. Arterioscler Thromb Vasc Biol 2004; 24: e13-8.

32. Lebovitz HE. Insulin resistance: definition and consequences. Exp Clin Endocrinol Diabetes 2001; 109 Suppl 2: S135-48.

33. Asrih M, Jornayvaz FR. Metabolic syndrome and nonalcoholic fatty liver disease: is insulin resistance the link? Mol Cell Endocrinol 2015; 418: 55-65.

34. Ferrannini E, Mari A. How to measure insulin sensitivity. J Hypertens 1998; 16: 895-906.

35. Bonora E, Targher G, Alberiche M, et al. Homeostasis model assessment closely mirrors the glucose clamp technique in the assessment of insulin sensitivity: studies in subjects with various degrees of glucose tolerance and insulin sensitivity. Diabetes Care 2000; 23: 57-63.

36. Geloneze B, Vasques AC, Stabe CF, et al. HOMA1-IR and HOMA2-IR indexes in identifying insulin resistance and metabolic syndrome - Brazilian Metabolic Syndrome Study. Arq Brasil Endocrinol Metabol 2009; 53: 281-7.

37. Szurkowska M, Szafraniec K, Gilis-Januszewska A, et al. Wskaźniki insulinooporności w badaniu populacyjnym i ich wartość predykcyjna w określeniu zespołu metabolicznego. Przegl Endokrynol 2005; 59: 743-51.

38. Gayoso-Diz P, Otero-Gonzalez A, Rodriguez-Alvarez MX, et al. Insulin resistance index (HOMA-IR) levels in a general adult population: curves percentile by gender and age. The EPRICE study. Diabetes Res Clin Practise 2011; 94: 146-55.

39. Gutch M, Sukriti Kumar S, Razi SM, et al. Assessment of insulin sensitivity/resistance. Indian J Endocrinol Metab 2015; 19: 160-4.

40. McAuley KA, Williams SM, Mann JI, et al. Diagnosing insulin resistance in the general population. Diabetes Care 2001; 24: 460-4.

41. Szosland K, Lewiński. A In quest for method of insulin resistance assessment in everyday clinical practice - insulin resistance indices. Diabetes Metab Syndr 2016; 10: 120-5.

42. Lakshmi C. Hormone therapy in acne. Indian I Dermatol Venereol Leprol 2013; 79: 322-37. 
43. Smith TM, Gilliland K, Clawson GA, et al. IGF-1 induces SREBP-1 expression and lipogenesis in SEB-1 sebocytes via activation of the phosphoinositide 3-kinase (PI3-K)/Akt pathway. J Investig Dermatol 2008; 128: 1286-93.

44. Nagpal M, De D, Handa S, et al. Insulin resistance and metabolic syndrome in young men with acne. JAMA Dermatol 2016; 152: 399-404.

45. Del Prete M, Mauriello MC, Faggiano A, et al. Insulin resistance and acne: a new risk factor for men? Endocrine 2012; 42: 555-60.

46. Kartal D, Yildiz H, Ertas $\mathrm{R}$ et al. Association between isolated female acne and insulin resistance: a prospective study. G Ital Dermatol Venereol 2016; 151: 353-7.

47. Balta I, Ekiz O, Ozuguz $P$, et al. Insulin resistance in patients with post-adolescent acne. Int J Dermatol 2015; 54: 662-6.

48. Cetinözman F, Aksoy DY, Elçin G, et al. Insulin sensitivity, androgens and isotretinoin therapy in women with severe acne. J Dermatol Treatment 2014; 25: 119-22.

49. S3-Guideline for the Treatment of Acne. European Dermatology Forum 2016.

50. Akhavan A, Bershad S. Topical acne drugs. review of clinical properties, systemic exposure, and safety. Am J Clin Dermatol 2003; 4: 473-92.

51. Fox L, Csongradi C, Aucamp M, et al. Treatment modalities for acne. Molecules 2016; 21: 1063.

52. Zaenglein AL, Pathy AL, Schlosser BJ, et al. Guidelines of care for the management of acne vulgaris. J Am Acad Dermatol 2016; 74: 945-73.

53. Fluhr JW, Degitz K. Antibiotics, azelaic acid and benzoyl peroxide in topical acne therapy. J Dtsch Dermatol Ges 2010; 8 Suppl 1: S24-30.

54. Bagatin E, de Freitas THP, Machado MCR, et al. Adult female acne: a guide to clinical practice. An Brasil Dermatol 2019; 94: 62-75.

55. Clayton RW, Göbel K, Niessen CM, et al. Homeostasis of the sebaceous gland and mechanisms of acne pathogenesis. Br J Dermatol 2019; 181: 677-90.

56. Melnik BC. p53: key conductor of all anti-acne therapies. J Transl Med 2017; 15: 195.

57. Cong TX, Hao D, Wen X, et al. From pathogenesis of acne vulgaris to anti-acne agents. Arch Dermatol Res 2019; 311 337-49.

58. Dikicier BS. Topical treatment of acne vulgaris: efficiency, side effects, and adherence rate. J Int Med Res 2019; 47: 2987-92.

59. Soyuduru G, Ösoy Adışen E, Kadıoğlu Özer, et al. The effect of isotretinoin on insulin resistance and adipocytokine levels in acne vulgaris patients. Turk J Med Sci 2019; 49: 238-44.

60. Jensterle $M$, Janez A, Mlinar B, et al. Impact of metformin and rosiglitazone treatment on glucose transporter 4 mRNA expression in women with polycystic ovary syndrome. Eur J Dermatol 2008; 158: 793-801.

61. Yang J, Holman GD. Long-term metformin treatment stimulates cardiomyocyte glucose transport through an AMPactivated protein kinase-dependent reduction in GLUT4 endocytosis. Endocrinology 2006; 147: 2728-36.

62. Rena G, Hardie DG, Pearson ER. The mechanisms of action of metformin. Diabetologia 2017; 60: 1577-85.

63. Melnik BC, Schmitz G. Role of insulin, insulin-like growth factor-1, hyperglycaemic food and milk consumption in the pathogenesis of acne vulgaris. Exp Dermatol 2009; 18: 833-41.

64. Behrangi E, Sadeghi S, Sadeghzadeh-Bazargan, et al. The effect of metformin in the treatment of intractable and late onset acne: a comparison with oral isotretinoin. Iran J Dermatol 2019; 22: 47-52.

65. Fabbrocini G, Izzo R, Faggiano A, et al. Low glycaemic diet and metformin therapy: a new approach in male subjects with acne resistant to common treatments. Clin Exp Dermatol 2016; 41: 38-42.

66. Gabaton N. DB-RCT on the efficacy and safety of metformin adjunct to lymecycline and topical adapalene/BP gel in mod-severe acne. World Congress Fund Poster Abstract Book American Academy of Dermatology 2016: 3.

67. Robinson S, Kwan Z, Tang MM. Metformin as an adjunct therapy for the treatment of moderate to severe acne vulgaris: a randomized open-labeled study. Dermatol Therapy 2019; 32: e12953.

68. Bubna AK. Metformin - for the dermatologist. Indian J Pharmacol 2016; 48: 4-10.

69. Forouzani-Haghighi B, Ashrafi H, Saki N, et al. The potential role of metformin in relieving acne vulgaris by modifying the impaired cellular signaling pathway, responsible for acne pathogenesis. Int Pharm Acta 2018; 1: 151-2. 